\title{
A 'real puzzle': the views of patients with epilepsy about the organisation of care
}

\author{
Glyn Elwyn*1, Stuart Todd 2 , Richard Hibbs ${ }^{3}$, Ajay Thapar ${ }^{2}$, Peter Edwards 3 , \\ Amanda Webb ${ }^{3}$, Clare Wilkinson ${ }^{2}$ and Mike Kerr ${ }^{2}$
}

\begin{abstract}
Address: ${ }^{1}$ Primary Care Research Group Swansea Clinical School University of Wales Swansea SWANSEA SA2 8PP, UK, ${ }^{2}$ Department of General Practice University of Wales College of Medicine Heath Park Cardiff CF4 4XN, UK and ${ }^{3}$ CAPRICORN primary care research alliance Croesnewydd Hall Wrexham Technology Park WREXHAM LL13 7YP, UK

Email: Glyn Elwyn* - g.elwyn@swansea.ac.uk; Stuart Todd - toddsp@cardiff.ac.uk; Richard Hibbs - bureau@extra-ibs.com; Ajay Thapar - thaparak@Cardiff.ac.uk; Peter Edwards - dr.peter.edwards@ntlworld.com; Amanda Webb - ajgors@bun.com; Clare Wilkinson - wilkinsonc@cardiff.ac.uk; Mike Kerr - kerrmp@cf.ac.uk

* Corresponding author
\end{abstract}

Published: 22 April 2003

BMC Family Practice 2003, 4:4
Received: 3 December 2002

Accepted: 22 April 2003

This article is available from: http://www.biomedcentral.com/I47|-2296/4/4

(C) 2003 Elwyn et al; licensee BioMed Central Ltd. This is an Open Access article: verbatim copying and redistribution of this article are permitted in all media for any purpose, provided this notice is preserved along with the article's original URL.

\begin{abstract}
Background: Little is known about how individuals who have a diagnosis of epilepsy have experienced healthcare services or their views about how they should best be organised to meet their ongoing needs.
\end{abstract}

Methods: Focus group interviews. Individuals with epilepsy were identified in 5 practices in Wales: 90 were invited, 40 confirmed attendance and 19 individuals attended interviews in 5 groups of size 6, 5, 4, 3 and I (Table 2). Inclusion criteria: individuals with a confirmed diagnosis of epilepsy, aged between 18-65. The exclusion criteria were learning disability or an inability to travel to interview locations.

Results: The individuals in these group interviews were not 'epilepsy activists' yet they remained critical in extended discussions about the services encountered during their patient careers, wanting more information and advice about how to adapt to problems, particularly after initial diagnosis, more involvement in decision making, rapid access to expertise, preferably local, and improved communication between clinicians. A central concern was the tendency for concerns to be silenced, either overtly, or covertly by perceived haste, so that they felt marginalised, despite their own claims to own expert personal knowledge.

Conclusions: Users of existing services for epilepsy are critical of current systems, especially the lack of attention given to providing information, psychosocial support and the wishes of patients to participate in decision making. Any reorganisation of services for individuals with epilepsy should take into account these perceived problems as well as try to reconcile the tension between the distant and difficult to access expertise of specialists and the local but unconfident support of generalists. The potential benefit of harnessing information technology to allow better liaison should be investigated. 


\section{Background}

Epilepsy affects almost $1 \%$ of the population and is a condition that combines burden, risk and complexity. It is a condition where primary care typically plays a passive role, reacting to problems and providing medication initiated by specialists. There is a perception that fragmenting the care across different sectors, with significant variation between regions, causes problems in the accessibility, equity and quality of care. Attention has been repeatedly drawn to such problems in working parties and reports [1-3]. The recurrent themes are the lack of clear clinical pathways and poor liaison between healthcare professionals. These concerns remain valid according to a recent assessment by the Clinical Standards Advisory Group (CSAG) [4]. These reports highlight the gap between aspirations and actual practice.

Audits in primary care have revealed that, when measured against professionally set criteria, clinical records provide little evidence that standards are met [5-7] and it is known that the majority of general practitioners have low confidence in their ability to manage epilepsy [8]. Yet manpower calculations indicate that specialists could not possibly provide a timely, equitable service to this group of patients [4]. Given this longstanding but largely professional debate, it was considered important to seek the views of people who have direct experience of epilepsy. Although we identified many surveys [9-14], few studies have examined patient perspectives in any depth $[15,16]$, and we could not find research that had sought views on service design or using focus groups of patients. A qualita- tive study was therefore performed to explore the experiences of individuals who have a diagnosis of epilepsy and their views about how services should best be organised.

\section{Methods}

Five practices in a primary care research alliance identified all patients diagnosed as having epilepsy and sent them information about the study, and consent procedures. Ethical approval was obtained from the Multicentre Research Ethics Committee (Wales) and all relevant Local Research Ethics Committees. Clinicians in each practice, assisted by the project researcher (AW), identified patients by searching for relevant computer codes and anticonvulsant medication. The records were checked to ensure that the inclusion criteria were fulfilled (adults aged 18-65 with confirmed diagnoses). Patients with learning disabilities or immobility were excluded in view of the logistics of focus group design. Eligible individuals were invited to participate in focus group interviews at a non-clinical setting such as a community hall. Five focus group interviews (with 8 participants), with equal number of males and females, were proposed. Participants completed the consent process and details about the topics for discussion were then introduced in the form of a pre-interview questionnaire containing 5 prompts (care, satisfaction, impact, skills, information). The interviews were moderated by a social scientist (ST), an experienced facilitator, who use open questioning to probe pertinent issues further. All topic areas reported in this article, with the exception of information exchange, are summarised in Table 1.

Table I: Topic areas for focus group interviews

-What are your reflections about receiving care for epilepsy?

- Should family doctors have greater involvement in the care of patients with epilepsy?

-What kind of care (organisational issues) do you think patients with epilepsy should receive?

Table 2: Invitation and attendance at focus groups

\begin{tabular}{|c|c|c|c|c|c|c|}
\hline \multirow[t]{2}{*}{ Practice } & \multicolumn{2}{|c|}{ Invitation } & \multicolumn{2}{|c|}{ Confirmation } & \multicolumn{2}{|l|}{ Attendance } \\
\hline & $M$ & $\mathbf{F}$ & $\mathbf{M}$ & $\mathbf{F}$ & M (Age) & F (Age) \\
\hline Powys & 7 & 2 & 1 & 1 & I (60) & \\
\hline Deeside & 12 & 10 & 4 & 2 & $3(31,33,46)$ & $2(44,65)$ \\
\hline Cardiff & 20 & 15 & 5 & 5 & $3(35,39,46)$ & $3(27,30,31)$ \\
\hline Dyfed & 9 & 7 & 3 & 1 & $3(53,58,62)$ & I (47) \\
\hline \multirow[t]{2}{*}{ Swansea } & 5 & 3 & 2 & 1 & $2(19,63)$ & I (39) \\
\hline & & 90 & & & & 19 \\
\hline
\end{tabular}




\section{Coding and analysis}

Transcripts of focus group interviews were read for recurring themes in participants' accounts, coded and analysed by a qualitative researcher (ST). Analysis of data was an inductive process aiming to discover both shared points and contrasting viewpoints. AW validated the themes and findings. The codes were reformulated into broader conceptual domains within which the similarities and variations, for example in the use of metaphor, were considered. The domains are those presented as sub-headings and representative quotes were selected. Personal and geographical identifiers have been removed. An executive summary was sent to the participants for comment and validation. No requests for changes were received.

\section{Results}

\section{Patient recruitment}

Although patient identification was straightforward, recruitment proved difficult. We invited 90 patients, obtained 40 confirmed participants and 19 people attended (12 male and 7 female). Many patients expressed an interest, consented, confirmed an attendance date but did not attend. We speculated about the possible explanations for this pattern and concluded that for many it would have been the first time that others in the same community would have become aware of their diagnosis, and that they became anxious about this exposure. A number of practical problems were also met, such as late snowfalls. Despite the difficulties, 5 interviews were achieved (4 groups and 1 individual). The small size may well have bolstered patients' confidence to voice their opinions. Attendees were drawn from practices in mid and west Wales, Deeside, a council estate in Cardiff and a suburb of Swansea (Table 2). Participants represented individuals who were not 'epilepsy activists' [17], i.e. not members of support societies and who had never previously been involved in any consultations about epilepsy services.

\section{Living and coping with epilepsy}

Every group made unprompted positive statements welcoming, what was for all of them, a first opportunity to share their views about the services provided for people with epilepsy. Without exception, the individuals were pleased that there was interest in their experiences and thoughts about how services should be planned.

Initial comments were about the reorientation that occurs when individuals receive a diagnosis. Across all the groups, it was felt that society in general rejected or disregarded people with epilepsy:

P Thing is, it's a thing you don't talk about... Em... but if you got epilepsy and you go somewhere and you tell them, you get blocked off. I've had experience of it.
There had been no previous opportunities to share illness narratives, which, as Frank notes, do not simply describe experiences but provide a platform to confer legitimacy to coping strategies [18]. Participants felt that managing epilepsy was more than a medical responsibility but one that involved significant personal work; an aspect that participants felt was poorly understood by clinicians. They admitted to being unable to express this view openly:

P It would be something if they could hear us talk. Just for them to listen. I'm sure most of us clam up in front of doctors.

Accommodating epilepsy was a task that required constant surveillance regardless of the degree of seizure control achieved. Finding ways of minimising the disruptive influences was regarded as an important personal achievement. But only a minority of participants reported clinicians showing an interest in these broader issues. Participants reported that the psychosocial problems associated with epilepsy were given little credence despite the significant, enduring and frustrating impact on relationships, employment and other activities. The achievement of mastery over the illness was a highly valued concept, which the participants wanted clinicians to explore and respect. However, there was no evidence that this assertive approach, openly voiced in the group setting, was extended to taking issue with professionals. Although some individuals acknowledged that clinicians had helped them gain this mastery, there was also a generalised concern that medical interventions might disrupt, or make redundant, their own coping strategies:

P I haven't seen a doctor for five years. I'm terrified that they'll change things or start mucking around with me. As it is now, I've nothing and that's how I want to keep it. I don't want to go back to a fit every six or seven months. I can be normal. I don't want it mucked up.

\section{Patient information and decision support}

The majority of participants felt frustrated at the lack of opportunity to take a more active part in their encounters with professionals and felt excluded from participating in their own care. They complained about how little time they had been given to discuss matters of importance to them in either primary or secondary care sectors:

P There's not much time given to you. If you're lucky you might get to ask one or two questions. You've been waiting for hours, traveled all this way just for few minutes then its home again. It's a bit of a waste of time and it could be done locally.

The tendency to minimise participant contribution and the implicit assumptions that patients would act as passive recipients of medical advice and treatment was also widely criticised: 
$\mathbf{P}$ They try you on tablets but they don't listen to how they make you feel. I know what my attacks are like and how they change.

Participants identified a lack of support, particularly at the start of patient careers:

P There was no support at all when I first found out, nothing at all... people weren't telling me anything. So you just have to get on with it really. I had to find out things for myself. My general practitioner didn't know much. I don't think its changed much in seventeen years. My general practitioner has never sat me down and talked to me about epilepsy or how I should deal with it. So I don't go there for help, they're not specialists are they? I know more than they do!

For many participants, the lack of time and encouragement to express their concerns led to problems, especially after initial diagnosis:

P The early months were worse. Nobody supports you then, not really! That's the vital time. I remember saying I was frightened and he said, 'Everybody is!' It was a bit of brush-off.

\section{Experience of services and suggestions for change}

A general concern was the difficulty accessing specialist clinics and the waiting time for first appointments. In addition, there was general support for the view that consultations in outpatient clinics were often pointless, the more so because expectations had been raised:

P You have to take a day off work to see a specialist. I waited for months and that's just because I got a cancellation. But it's the whole day just for five minutes and, "How are things? Fine! OK... then carry on. See you next time."

The importance of support and trust is further underlined when participants were asked to recall high quality encounters with medical services. A young man, recently diagnosed, who had not spoken to a general practitioner about his condition, was urged to do so on the basis that it was possible to obtain satisfactory services in primary care:

P I like my practice. They'll talk about it there. There's not many people you can talk to, not really. See with me, people think I've nothing to cope with because I haven't got, you know, fits. But I think they're approachable. They treat you like a person. I try and see the same one all the time because I think he knows. He's really good with epilepsy and I trust him. I don't really know how knowledgeable he is but I do know he'll refer me if needs be. I don't want someone just to be nice to me.

Nevertheless, most participants held few expectations about general practitioner expertise:
P19 Well mine doesn't have a clue about epilepsy. But they're not qualified to, are they?

P16 This is it, they might be generalists but they can still listen. I don't feel guilty talking about my fears.

P17 You know his brother had epilepsy?

P16 No? So that's it. That explains it, he knows what it's like to travel down that dark road.

Low expectations did not however exclude generalists from criticism. Many were perceived as poor listeners and unable to explore patient concerns. The resulting need to request specialist referral was regarded as face threatening task, the more so if it was felt that the concerns should have been dealt with in primary care:

P I do have hesitations about asking to see a specialist. I think a specialist knows more than a general practitioner ever will about epilepsy. It's like asking permission, its awkward. And I know it's just that I've got a few questions.

There were some participants who felt that general practitioners could and should have a greater understanding of epilepsy so that the delays and disruption of a visit to outpatient clinics could be avoided:

P2 I don't think they [general practitioners] know enough really, not really!

P3 They know nothing as far as I'm concerned!

P4 My GP's pretty knowledgeable. Sure some of them probably don't. But I'd like to think if they didn't they send you to someone who does.

P3 But don't you think if they stopped and listened, like take a bit more time and talk to us, maybe they'd learn.

P4 Maybe they could deal with some of the smaller issues. Like I find my epilepsy is brought on by stress. So I'm up and down the hospital most of the time. I don't need that in my life. My general practitioner could deal with stress things. If that were dealt with, that would deal with the epilepsy.

P3 I don't know, I go to the hospital; I give them ten out of ten. I've a lot of faith in them.

Severe criticisms emerged when the patients recounted their unmet expectations in specialist settings. Some were reserved about seeing specialists and viewed them as more likely to alter management plans, without involving the patient. The patients did express sympathy with the time pressures they witnessed in clinics and made allowances 
for shortcomings in the service they received by attributing them to a lack of resources rather than to professional shortcomings:

P They've only got five minutes. Unless you go private. I feel sorry for them. The nurse walks in front of you - gives him a file - and you're expecting him to be a genius. He's only just opened it - no way! He's probably-well, how many piles of files does he see in a day and then multiply that by God knows how many!

Dissatisfaction with services was much more pronounced when participants felt they had received inappropriate and ineffective treatment:

P It was a number of years before I got mine sorted. I'd been waiting for months and my wife made me go private. So I had eighteen years of not having well-controlled epilepsy because I wasn't getting the right treatment.

Some participants were also aware that there were different types of 'specialists'. One patient, after realising he had been seen for many years in a psychiatric service (a specialty that does not normally offer expertise in this area) heard about the existence of an epilepsy clinic:

P I insisted I went there. The tonic-clonic seizures stopped. I was still getting queer sensations. They told me to take one more tablet and I've been seizure free for four years. I feel angry that I put up with someone who wasn't an epilepsy specialist for 20 years.

Participants felt that the design of epilepsy services should be tailored to specific requirements. For those who felt their epilepsy was largely well controlled (i.e. 'seizure and symptom free') the overwhelming view was that consulting a specialist was a waste of their time. The patients who were stable and had achieved an acceptable quality of life wanted their general practitioner to take on a more active role, although some doubted if the inclination or knowledge to do so existed. There was no perceived need by these participants for regular monitoring to take place in primary care.

\section{Discussion \\ Principal findings}

Interview participants were not 'epilepsy activists' yet remained critical in extended discussions about the services experienced during their patient careers, wanting more information and advice about how to adapt to problems, particularly as they adjusted to the diagnosis, more involvement in decision making, rapid access to expertise, preferably local, and improved communication between clinicians. A central concern was the tendency for concerns to be silenced, either overtly, or covertly by perceived haste so that they felt marginalised, despite their own claims to own expert personal knowledge. Many clinicians appeared to them to lack interest in their views about seizure precipitants and proposed, or already enlisted, coping or avoidant strategies. Participants recounted that this often led to mismatched explanatory models [19] and an imposition of management suggestions that were often impossible to implement. Their feelings were reinforced by their recollections of successful relationships with professionals, i.e. those who had listened, understood contextual constraints and provided personalised guidance. Although dissatisfied with existing access to skilled help, participants did not support the concept of regular monitoring, preferring to make their own judgments about the need to seek help.

\section{Strengths and Weaknesses}

The strength of this work lies in the in-depth analysis of patient narratives voiced in group settings, which offered safety to raise concerns and increased confidence to raise issues that normally remain unmentioned. Two significant weaknesses also exist: recruitment to the group interviews was less than proposed and the participants may represent self-selected negative viewpoints that were reinforced by the interview method. Secondly, although the participants were asked to propose different or new structures for epilepsy services, their views were not well formulated and had to be interpreted by the research team on the basis of their dissatisfaction with existing systems. The results however confirm previous work showing that not enough time is given to provide support [15], that the psychosocial dimension of epilepsy is given little credence [16] and that patients are seldom seen as legitimate agents in the management of their epilepsy $[15,20]$.

\section{Implications for clinicians or policymakers}

Participants felt that changes to existing services should involve increased attention to information and psychosocial support at diagnoses, and faster access to appropriate levels of expertise when problems occur. The emphasis given to patient participation should alert clinicians to consider increasing their skills in sharing decisions [21], a finding that confirms previous work in this area [22]. When translated into practical needs, it appears that the diagnosis of epilepsy should be accompanied by an approach that combines purposively designed information, tailored for differing educational levels, with access to psychosocial support. Methods that assist decision making or provide examples of illness experiences, e.g. DIPEX http:/ /www.dipex.org may be useful solutions. In terms of the personnel required, the recent CSAG report recommended that secondary care based 'epilepsy centres' be established for cohorts of 5000 patients (i.e. catchment populations of 500,000), with significant new investment made in nurse-led services [4], but there is no indication that these suggestions will be implemented. Those who 
argue that the care of epilepsy should be based on a specialist model [23] have underestimated the impracticality of the suggestion. But it is also equally unrealistic to expect all general practices given the current organisation of primary care in the UK to provide high quality services to patients with epilepsy [24]. It is also important to realise that when 'stable' patients may resist regular review, anxious about the prospect of change leading to renewed problems [22].

\section{Unanswered questions and future research}

Although difficult to speculate, perhaps it's time to consider the concept of developing generalists (medical or nurse-led) at a local level who have the expertise to deal with the clinical needs of people with epilepsy as well as the skills to address the broader psychosocial problems [25]. These generalists could be supported by specialists using innovative methods of communication such as asynchronous email with agreed minimum datasets. Meanwhile, there is no doubt that patients with epilepsy pose a 'real puzzle'. It is an example of a clinical condition where marginal changes to the generalist model to encourage special interests coupled with efficient information exchange between primary and secondary care could transform patient experiences.

\section{Authors' contributions}

GE and AT designed the study, GE co-ordinated the work and wrote the article. ST and AW conducted the focus groups and undertook the analysis. RH managed the project and obtained ethical approval for the study. PE, CW and MK acted as advisers to the study. GE acts as guarantor for the paper. The majority of patients wish to be involved in future policy and service developments and have been given the opportunity to comment on this publication and contribute to an online forum.

\section{Acknowledgements}

This work was undertaken by CAPRICORN, a primary care research alliance that receives funding from the $\mathrm{Na}$ tional Assembly for Wales, and specifically by a Wales Office of Research and Development for Health and Social Care grant (Number: SG99/252).

\section{Competing interests}

None declared.

\section{References}

I. Ministry of Health National Assitance Act 1948: Welfare of Handicapped Persons: the special needs of epileptics and spastics Ministry of Health: London 1953,

2. Reid JA People with epilepsy: report of a Joint Sub-Committee of the Standing Medical Advisory Committee and the Advisory Committee on the Health of Handicapped Persons Central Health Services Council: London 1969.

3. Winterton PMC Report of the working group on services for people with epilepsy: a report to the Department of Health and Social Security The Department of Education and Science and the Welsh Office. HMSO: London 1986,

4. Clinical Standards Advisory Group Services for Patients with Epilepsy Clinical Standards Advisory Group: London 1999,

5. Thapar AK Care of patients with epilepsy in the community: will new initiatives address old problems Br J Gen Pract 1996, 46:37-42

6. Redhead K, Tasker P, Suchak K, Mumatz A, Copsey G, Roberts P, Daws J and Titmarsh M Audit of the care of patients with epilepsy in general practice $B r J$ Gen Pract 1996, 46:73I-734

7. Jacoby A, Graham-Jones S, Baker G, Ratoff L, Heyes J, Dewey M and Chadwick $D$ A general practice records audit of the process of care for people with epilepsy $\mathrm{Br} J$ Gen Pract 1996, 46:595-599

8. Thapar AK, Stott NCH, Richens A and Kerr M Attitudes of general practitioners to the care of people with epilepsy Family Practice 1998, 15:437-42

9. Mills N, Bachmann M, Harvey I, McGowan M and Hine I Patients' experiences of epilepsy and health care Family Practice 1997, 14:117-23

10. Jain P, Patterson VH and Morrow JI What people with epilepsy want from a hospital clinic Seizure 1993, 2:75-8

II. Chappell B Epilepsy: patient views on their condition and treatment Seizure 1992, I:102-9

12. Crawford $P$ and Lee $P$ Women with epilepsy: their views about their treatment and care Seizure 1999, 8:398-403

13. Poole K, Moran N, Bell G, Solomon J, Kendall S, McCarthy M, McCormick D, Nashef L, Johnson A, Sander J and Shorvon S Patients' perspectives on services for epilepsy: a survey of patient satisfaction, preferences and information provision in 2394 people with epilepsy Seizure 2000, 9:55I-8

14. Chappell $B$ and Smithson WH Patient views on primary care services for epilepsy and areas where additional professional knowledge would be welcome Seizure 1998, 7:447-57

15. Ridsdale L, Morgan M and O'Connor $C$ Promoting self-care in epilepsy: the views of patients on the advice they have received from specialists, family doctors and an epilepsy nurse Patient Education and Counseling 1999, 37:43-7

16. Wallace HK and Solomon JK Quality of epilepsy treatment and services: the views of women with epilepsy Seizure 1999, 8:8I-7

17. Arnston $P$ The perceived psychosocial consequences having epilepsy in Psychopathology in epilepsy: social dimensions (Edited by: Whitman S, Hermann B, Editors) Oxford University Press: Oxford 1986,

18. Frank $A W$ The rhetoric of self-change: illness experience as narrative The Sociological Quarterly 1993, 34:39-52

19. Kleinman A The illness narratives New York: Basic Books 1988,

20. Coulter A Paternalism or partnership? BMJ 1999, 3 19:7 I9-794

21. Elwyn G, Edwards A, Kinnersley $P$ and Grol R Shared decision making and the concept of equipoise: defining the competences of involving patients in healthcare choices $\mathrm{Br} J$ Gen Pract 2000, 50:892-899

22. Ridsdale $L, K$ wan $I$ and Morgan $M$ How can a nurse intervention help people with newly diagnosed epilepsy? A qualitative study of patients' views Seizure 2002, I I:I-15

23. Callaghan $N$ The role of the neurologist in epilepsy management - a neurologist's view Seizure 1994, 3:8I-83

24. Ridsdale $L$ Matching the needs with skills in epilepsy care $B M]$ 1995, 310:1219-20

25. Rogers $G$ The future of epilepsy care in general practice... a role for the GPWsi? B J Gen Pract 2002, 483:872-3

\section{Pre-publication history}

The pre-publication history for this paper can be accessed here:

http://www.biomedcentral.com/1471-2296/4/4/prepub 